\title{
What's in store for a whistleblower?
}

\author{
oshua Richmond knew that the \\ procedure he performed on a rat \\ was not approved by Great Eastern \\ University's IACUC. He had reminded \\ Dr. Paul Levine, his graduate studies \\ mentor, that they needed IACUC approval \\ before initiating the procedure, but Levine \\ became irate, as he often did, and told \\ him to do what he was told to do or find \\ another lab to work in. That was not \\ a desired option for Richmond, so he \\ performed the procedure. \\ Still bothered by the incident after a few \\ months had passed, Richmond wrote an \\ anonymous letter to the IACUC, relating the \\ noncompliance. When the IACUC began its \\ investigation, the rat was long gone. When \\ confronted with the accusation, Levine \\ denied the claim and demanded to know \\ who his accuser was because the university's \\ bylaws specified that a faculty member \\ accused of wrongdoing had a right to know \\ his or her accuser. Richmond denied writing \\ the letter but eventually admitted that he \\ performed the procedure. Levine did not \\ think Richmond was the whistleblower, \\ assuming that would be too obvious; \\ however, because Richmond was the only \\ person working for him, he told Richmond \\ to find another mentor, as he was no longer \\ welcome in his laboratory.
}

Distressed by the impending loss of his job and possibly revealing himself as the letter writer, Richmond began reading. The school's IACUC policy manual stated that the identity of a whistleblower would remain confidential if that was the preference of the whistleblower, but the policy said nothing about protection from reprisals. Nevertheless, he was somewhat heartened to find that the Guide for the Care and Use of Laboratory Animals stated that "The process [of reporting concerns] should include a mechanism for anonymity, compliance with applicable whistleblower policies, nondiscrimination against the concerned/reporting party, and protection from reprisals." ${ }^{\prime \prime}$ Richmond told the IACUC that Levine obviously imposed a reprisal against him, but the IACUC chair opined that the Guide was only referring to reprisals against a known whistleblower. The IACUC chair was also concerned with the comment in the Guide about protection from reprisals because a document from the federal Office of Laboratory Animal Welfare (OLAW), stated that "OLAW may withhold identifying information to protect whistleblowers, but protection from reprisal for whistleblowers must be addressed at the institutional and/or state level."
Is Richmond both a whistleblower and the target of a reprisal even though he denied writing the letter? Is there a conflict between the OLAW statement which assigns responsibility against reprisals to the institution or state, and the Guide, which is incorporated into the PHS Policy ${ }^{3,4}$ and appears to expect an institution to provide protection from reprisals? Should Richmond tell the whole truth and look for another lab? How should the IACUC deal with these issues?

\section{Jerald Silverman ${ }^{凶}$ \\ University of Massachusetts Medical School, \\ Worcester, MA, USA. \\ $\bigotimes_{e-\text { mail: Jerald.Silverman@umassmed.edu }}$}

Published online: 27 May 2020

https://doi.org/10.1038/s41684-020-0551-z

References

1. Institute for Laboratory Animal Research. Guide for the Care and Use of Laboratory Animals. $8^{\text {th }}$ edn. (National Academy Press, Washington, DC. 2011).

2. Office of Laboratory Animal Welfare, National Institutes of Health. Reporting Noncompliance. https://olaw.nih.gov/guidance/ reporting-noncompliance.htm

3. Public Health Service. Policy on Humane Care and Use of Laboratory Animals. (US Department of Health and Human Services, Washington, DC. 1986, amended 2002).

4. Office of Laboratory Animal Welfare, National Institutes of Health. What Investigators Need to Know About the Use of Animals. https://grants.nih.gov/grants/olaw/InvestigatorsNeed2Know.pdf

\section{Protect the gatekeeper}

$\mathrm{T}$ his scenario investigates whistleblower protection for reporting noncompliance issues in an animal research setting. Here, Richmond is an institutional laboratory employee that performed an animal research procedure without Great Eastern University's (GEU) Institutional Animal Care and Use Committee's (IACUC) approval, as instructed by his mentor Dr. Levine. As "conducting research animal activity without the IACUCs approval is a serious noncompliance with the Animal Welfare Act and Regulations," Richmond never should have performed the procedure without IACUC approval in the first place, but he risked losing his job with Levine's lab if he refused to conduct the experiment.

After some time passed, and in good faith, Richmond anonymously sent a letter to GEU's IACUC reporting the allegation; he then later denied doing so when confronted. Richmond likely denied writing the letter in order to keep his job, but, as no one else was involved with the procedure, he had to leave the lab once Levine knew that no one else could have reported the noncompliance. Therefore, Richmond appeared to be a whistleblower and a target of reprisal.

As Richmond was let go from Levine's lab, there seems to be a conflict with the Office of Laboratory Animal Welfare (OLAW) and the Guide's statements that whistleblowers should be protected from retaliation by the state or institution. OLAW assigns responsibility against reprisals to the institution or state, and the Guide expects an institution to provide protection from reprisals ${ }^{2,3}$. If individuals report allegations of wrongdoing anonymously, every effort should be made to keep it that way. The regulatory agencies seem to want whistleblower protection, and the research institution should have a policy or Standard Operating Procedure in place to protect whistleblowers; otherwise, whistleblowers may not come forward due to fear of retaliation.

Ultimately, Richmond shouldn't have conducted the animal procedure in the first place. He should tell the whole truth and look for another lab to work in. There will be other labs in which to seek employment, and hopefully they'll be fully compliant. The IACUC meanwhile has the responsibility to investigate any animal concerns raised by whistleblowers. Institutional and IACUC contact information should be posted throughout all research facilities so anyone that has questions or concerns 